\title{
Perspectivas acerca do cuidado com a saúde das pessoas em situação de rua
}

\section{Perspectives on the health care of homeless people}

\section{Perspectivas sobre la atención de salud de las personas en situación de calle}

\author{
Fernanda Gomes Faria' ${ }^{10}$, Rodrigo Siqueira-Batista ${ }^{2,3}$ (1) \\ ${ }^{1}$ Universidade Federal Fluminense - Rio de Janeiro (RJ), Brasil. \\ 2Universidade Federal de Viçosa - Viçosa (MG), Brasil. \\ ${ }^{3}$ Faculdade Dinâmica do Vale do Piranga - Ponte Nova (MG), Brasil.
}

\section{Resumo}

Introdução: As pessoas em situação de rua (PSR) estão submetidas, cotidianamente, a significativos riscos, entre os quais se destacam aqueles atinentes à saúde. Objetivo: Discutir as principais questões relativas ao cuidado à saúde das PSR. Métodos: Realizou-se investigação teórica a partir da leitura e apreciação de textos e documentos atuais dirigidos ao tema, a fim de destacar (1) os conceitos chave apresentados e (2) a argumentação desenvolvida. Resultados e discussão: O caminho percorrido em tal empreitada considerou (1) a concepção de saúde-doença e as necessidades e demandas de saúde dessas populações, (2) as políticas públicas e o papel dos serviços na atenção à saúde da PSR e (3) o papel da Atenção Primária à Saúde (APSD), com ênfase no trabalho dos Consultórios na Rua. Conclusões: A sistematização reflexivo-crítica empreendida buscou a delimitação de elementos do aparato jurídico-social e ético-político que envolvem os processos de ampliação do cuidado de tais usuários.

Palavras-chave: Pessoas em situação de rua; Necessidades e demandas de serviços de saúde; Atenção primária à saúde; Políticas de saúde.

Como citar: Faria FG, Siqueira-Batista R. Perspectivas acerca do cuidado com a saúde das pessoas em situação de rua. Rev Bras Med Fam Comunidade. 2022;17(44):2548. https://doi.org/10.5712/rbmfc17(44)2548
Autor correspondente:

Rodrigo Siqueira-Batista

E-mail: rsbatista@ufv.br

Fonte de financiamento:

não se aplica.

Parecer CEP.

CAAE 68482117.5.0000.5243.

Procedência:

não encomendado.

Avaliação por pares:

externa.

Recebido em: 29/05/2020.

Aprovado em: 10/09/2021.

Editor Associado:

Antônio Augusto Dall'Agnol Modesto 


\begin{abstract}
Introduction: Homeless people (HP) are daily subjected to significant risks, among which those related to health stand out. Objective: To discuss the main issues related to the health care of HP. Methods: Theoretical research was carried out based on the reading and assessment of current texts and documents concerning the topic, in order to highlight (1) the key concepts presented and (2) the developed argumentation. Results: This endeavor considered (1) the concept of health-disease and the health needs and demands of these populations; (2) public policies and the role of services in the health care of HP; and (3) the role of Primary Health Care (PHC), with emphasis on the work of the Outdoor Clinics Program. Conclusions: This reflective-critical systematization sought the delimitation of elements of the legal-social and ethical-political apparatus that involve the processes of expansion of health care to such users.
\end{abstract}

Keywords: Homeless persons; Health services needs and demand; Primary health care; Health policy.

\title{
Resumen
}

Introducción: Las personas sin hogar (PSH) son sometidas diariamente a riesgos significativos, entre los que destacan las relacionadas con la salud. Objetivo: Discutir los principales temas relacionados con la atención de la salud del PSH. Métodos: Se realizó investigación teórica a partir de la lectura y apreciación de textos y documentos actuales dirigidos al tema, con el fin de resaltar (i) los conceptos clave presentados y (ii) la argumentación desarrollada. Resultados: El camino emprendido en esta tarea consideró (1) la concepción de la enfermedad-salud y las necesidades y demandas de salud de estas poblaciones, (2) las políticas públicas y el papel de los servicios en la atención sanitaria del PSH y (3) el papel de la Atención Primaria de Salud (APSD), con énfasis en el trabajo de las clínicas de la calle. Conclusiones: La sistematización reflexiva-crítica emprendida buscó la delimitación de elementos del sistema jurídico-social y ético-político que implican los procesos de expansión de la atención a dichos ususrios.

Palabras clave: Personas sin hogar; Necesidades y demandas de servicios de salud; Atención primaria de salud; Políticas de salud.

\section{INTRODUÇÃO}

O presente ensaio é fruto de uma pesquisa realizada no Programa de Pós-Graduação em Saúde Coletiva da Universidade Federal Fluminense (PPGSC/UFF), dirigida às reflexões sobre o cuidado da saúde das pessoas em situação de rua (PSR), especialmente no âmbito da Atenção Primária à Saúde (APS). Para tecê-las, tornou-se necessário direcionar as discussões à percepção dos sujeitos em relação:

1. Aos seus modos de cuidado;

2. Aos significados de saúde e de doença; e

3. As necessidades de acesso aos serviços de saúde.

Com efeito, na perspectiva de reconhecer o lugar no mundo desses usuários do Sistema Único de Saúde (SUS) - no caso, as PSR —, suas próprias noções de cuidado precisam ser consideradas, servindo de elemento de análise das práticas de saúde e de recurso para a legitimação de políticas públicas. ${ }^{1}$ A busca dessa nova configuração parte da necessidade de afirmação do ser humano como centro da ação ético-política manifesta como dimensão-cuidado. ${ }^{2}$

As realidades das PSR são marcadas por inúmeras vulnerabilidades sociais, referentes a um contínuo processo histórico de exclusão social. Por conseguinte, devem ser buscadas novas configurações para os serviços de saúde, as quais correspondam ao genuíno compromisso de cuidado para com esses sujeitos oprimidos. ${ }^{1,3}$ Desse modo, pensar novos referenciais exige um resgate da constituição de políticas públicas, leis, diretrizes e organizações de serviços que disponham de práticas de saúde para atender às demandas das PSR, bem como um aprofundamento da análise sobre as concepções de cuidado dessa população como forma de avaliar a potência de tal dimensão.

Com base nessas preliminares considerações, o escopo do presente manuscrito é: 
1. Apresentar as concepções atinentes aos processos saúde-doença-cuidado — com ênfase nas demandas e necessidades de saúde da população; e

2. Discutir os modos pelos quais esses fatores estão relacionados com a produção de cuidado e com a organização dos serviços e redes para a articulação das práticas em saúde.

Para isso, discutem-se o papel dos serviços nessa atenção, a efetivação das políticas públicas que os direcionam, além da elaboração teórica sobre as práticas do serviço do Consultório na Rua (CnaR) no bojo da APS.

\section{Concepção de saúde-doença e necessidades e demandas de saúde}

As conceituações acerca do binômio "saúde-doença" e dos problemas e necessidades de saúde, que se revelam condições e condicionantes dessa área, variam dependendo dos contextos nos quais são enunciados. Para além de suas etimologias e significados, é necessário ter um olhar amplo que considere o fenômeno expresso em seus mais diversos aspectos simultaneamente. ${ }^{4}$

A compreensão construída com base na antropologia da saúde e da doença pode ser considerada bastante significativa, pois:

1. Possibilita o diálogo sobre a multiplicidade de elementos que envolvem esse acontecimento; e

2. Oportuniza a argumentação sobre políticas de saúde menos segregacionistas e mais adequadas às necessidades das classes economicamente desprovidas, compreendendo os indivíduos e o seu trânsito pelos setores de atenção à saúde: ${ }^{5}$

O conceito de saúde reflete a conjuntura social, econômica, política e cultural. Ou seja: saúde não representa a mesma coisa para todas as pessoas. Dependerá da época, do lugar, da classe social. Dependerá de valores individuais, dependerá de concepções científicas, religiosas, filosóficas. O mesmo, aliás, pode ser dito das doenças. Aquilo que é considerado doença varia muito. ${ }^{5}$

O termo "saúde" também envolve um viés científico e filosófico, na medida em que se constitui como objeto complexo - conceitualmente elaborável e empiricamente apreensível —, analisável e perceptível, tendo em vista seus efeitos sobre as condições de vida dos sujeitos. Como objeto de conhecimento e operador de transformações, apresenta várias facetas reconhecidas: fenômeno, metáfora, medida, valor e práxis. ${ }^{6}$

Tal caracterização diz respeito às análises que comportam reflexões sobre o termo. Uma delas é a contribuição de Santos, ${ }^{7}$ autor que avalia a existência — ou não — da concepção de saúde. Quando esse autor afirma que "buscar a saúde é questão não só de sobrevivência, mas de qualificação da existência", torna-se evidente que para além da contextualização, no âmago da lógica social, é preciso concebê-la, a saúde, com um olhar dirigido:

a) às significações próprias — ou seja, para além do fundamento da cura ou da mera superação de algum mal-estar; e

b) às intempéries da própria existência considerada saudável e possível para os distintos sujeitos.

A complexidade do termo "saúde" está intimamente associada àquela expressa no vocábulo "doença". Ambos os conceitos atravessam, em suas significações, as esferas sociais e individuais; 
ademais, dizem respeito à dimensão biológica da existência, mas também à realidade historicamente construída por diferentes atores. ${ }^{8}$ Com efeito, torna-se essencial a reflexão sobre os modos pelos quais as pessoas vivem a saúde e a doença e sobre a formulação dos sentidos e das práticas relativas a tal binômio. Devem-se considerar, pois, as narrativas dos indivíduos, suas subjetividades e o caráter polissêmico dos discursos sobre as enfermidades. ${ }^{9}$ Sendo assim, pensar o processo saúde-doença implica analisar primeiramente as condições de vida dos sujeitos, suas biografias, as determinações históricosociais-ambientais e as influências contextuais que interferem em suas formas de perceber o próprio corpo. Além disso, pressupõe a identificação, ou não, dos elementos saudáveis e dos determinantes do adoecimento. Essa observação incorpora a consideração sobre a produção social da saúde e da doença, cuja atenção se volta para as relações entre as condições nas quais esta se manifesta. ${ }^{10}$

Esse questionamento está dirigido aos arranjos que não consideram a totalidade dos problemas de saúde - tornados "visíveis" nas narrativas dos indivíduos - conforme seus distintos condicionantes. ${ }^{11}$ Trata-se, pois, da lógica hegemônica, alicerçada no modelo biomédico, de acordo com o qual, para todos os efeitos, a saúde e a doença são redutíveis ao domínio orgânico. ${ }^{10}$ De outro modo, pensar o par saúde-doença deveria comportar a abrangência das condições de vida das pessoas, para além das manifestações inerentes ao corpo físico. ${ }^{9}$ Percebe-se, assim, a necessidade de estabelecer contato com as subjetividades, as relações e os contextos de vida dos sujeitos. Isso só se torna possível ao se aproximar dessas percepções e ao compreender, genuinamente, as representações das vivências de cada pessoa sobre si mesma, bem como seus modos de ser e de estar no mundo, dada a complexa articulação entre individualidade e coletividade..$^{12}$

Há de se reconhecer, também, que a manifestação da subjetividade perpassa por certa expressão invocada pela ideia da normatividade, de acordo com a qual a relação com o corpo está subsumida a um conjunto de regras e estilos de vida, os quais não permitem que o sujeito aja com autonomia. ${ }^{13}$ Ou seja, pensar em concepções de saúde e de doença requer que se considerem as padronizações sociais às quais as pessoas estão continuamente submetidas.

Diante dessas pontuações - e recorrendo à discussão inicial - pode-se considerar que saúde e doença representam um binômio não explicável, unicamente, pela dimensão biológica e, tampouco, pelas perspectivas filosófica, científica e existencial. Sobretudo, ele refere-se - também - a acontecimentos culturais, historicamente construídos de diversas formas, em sociedades diferentes, de modo que esse par de conceitos deverá ser analisado, necessariamente, também de um ponto de vista social, ou seja, como fato ocorrido em sociedade e vivenciado pelo indivíduo. ${ }^{8}$

Com efeito, a presente investigação está embasada em uma multiplicidade de olhares para pensar o fenômeno atual do cuidado com a saúde das PSR. É oportuno destacar alguns dos elementos que compõem os determinantes do processo saúde-doença dessa população. De fato, algumas situações devem ser consideradas como partícipes de tal binômio, tais como as circunstâncias de desemprego, de desestruturação familiar, de baixa escolaridade, de acesso limitado aos serviços públicos, de baixo grau de articulação comunitária e de falta de horizontes (quiçá, desesperança). ${ }^{14}$ Esses são aspectos que podem ser identificados em grande parte das PSR. Torna-se essencial, então, dimensionar as necessidades de saúde que precisarão ser acolhidas/atendidas para a devida organização dos serviços.

Além disso, é indispensável utilizar essas pontuações como elementos norteadores das investigações sobre a forma com que as concepções das PSR interferem em suas vidas, sobretudo em termos dos impactos na atuação dos serviços de saúde, no contexto das políticas públicas e do SUS. Trata-se, em última análise, de organizar o cuidado da saúde de modo a garantir o exercício da cidadania, assegurado 
pelo ordenamento jurídico vigente. Essas reflexões estendem-se - e são complementadas - pela indagação referente à percepção dos problemas de saúde, suas peculiaridades e influências, já que se trata de elementos que intervêm na capacidade explicativa dos fenômenos, afins ao processo saúdedoença, o que permite maior eficácia para a busca de melhor atenção às necessidades da população. ${ }^{15}$

Nesse contexto, destaca-se a problematização do que pode ser considerado uma questão de saúde e como seu entendimento abrange considerável complexidade:

"[...] o que é problema para uns pode não ser considerado problema para outros. A visão que se tem dos problemas de saúde, portanto, varia em função da posição dos distintos sujeitos na estrutura das relações sociais, fazendo parte de sua 'visão de mundo', de sua cultura, de seus projetos políticos, de suas utopias [...] Nesse sentido, a identificação dos problemas e necessidades de saúde da população tem que assumir, ou tentar assumir, uma 'visão policêntrica', identificando os diversos sujeitos e sua posição na 'estrutura de poder' em saúde. ${ }^{16}$

Essa colocação aponta para a autonomia do sujeito - enquanto verdadeiro detentor de conhecimento de si e de seus cuidados - , além de revelar como é necessário que ele seja reconhecido, em suas capacidades, como aquele que pode assinalar quais são os seus problemas e as suas demandas de saúde. Nesse caso, parte-se da premissa de que as necessidades de saúde se expressam pela cultura, valores, projetos e desejos dos sujeitos que procuram os serviços (por exemplo, os do SUS). ${ }^{15}$ Essa é uma perspectiva que, necessariamente, deve considerar o encontro entre quem demanda e quem oferece cuidado, bem como levar em conta os sentidos construídos nesse processo.

No âmbito da Saúde Coletiva, essa perspectiva é coerente com a composição do SUS, já que estão circunscritas, nas práticas de saúde, considerações acerca dos determinantes e condicionantes envolvidos no processo saúde-doença. São elementos que consubstanciam a exclusão de grande parte da população do sistema econômico, com a produção de interações sociais matizadas pelo individualismo, pelo consumo como atribuição de status e prestígio social e pela competição. ${ }^{17}$

As concepções de saúde também se estabelecem com base nas relações humanas-humanas e humanas-ambiente. ${ }^{18}$ Isso quer dizer que tanto a troca entre os sujeitos - suas experiências de vida e as relações que constituem com os outros - quanto o território com o qual eles se relacionam e que influencia significativamente no modo de vida individual e coletivo permitem a composição de aspectos que interferem em seu estado de saúde-doença. Nesse domínio, um fator inerente à lógica de cuidado é o contato com suas realidades, suas condições de existência individuais e coletivas, suas formas de ser e estar no mundo. Por esse motivo, pensar sobre o cuidado da saúde ratifica a existência de necessidades ampliadas, considerando-se ações complexas, para além das meramente curativas. ${ }^{19}$

Essa análise instiga o pensamento ao ressignificar continuamente os modos de cuidado convencionais e protocolares, em prol da ampliação da percepção do processo saúde-doença-cuidado enquanto elemento que dialoga com as necessidades reais de saúde, e não apenas com as ações voltadas à "melhoria compulsória e imediata" de uma dada enfermidade. Sendo assim, a análise ganha outra abrangência, aquela que compreende uma atenção feita longitudinalmente de forma cuidadosa e acolhedora em relação ao que cada indivíduo e o coletivo demandam.

Dessa forma, expande-se a análise de contextos nos termos de uma dimensão que compreenda os encontros da população - e suas culturas - com os cuidadores nos serviços de saúde; ou seja, reconhece-se a questão da atenção à saúde para além da qualidade do diagnóstico e do tratamento. 
Com efeito, trata-se de desenvolver ações que permitam alcançar um nível de profundidade inclusivo da visão de mundo daquele que necessita de amparo. ${ }^{20}$ Ademais, a imprevisibilidade do que se vai revelar enquanto acontecimento nesses encontros é inevitável. Para remediá-la, torna-se necessária a articulação constante entre aqueles que dialogam com os usuários e outros atores convocados que também estejam envolvidos nesse movimento. Sendo assim, é imprescindível, para que esse processo seja sensível ao que se produz nesses encontros, que se encontrem formas de cooperação entre a saúde e as demais políticas governamentais, para que ocorra uma atuação intersetorial. ${ }^{15}$

\section{As políticas públicas e o papel dos serviços na atenção à saúde das pessoas em situação de rua}

Pensar o sistema de saúde e a disposição dos serviços de atenção à população requer avaliar a forma com que as concepções de saúde e de doença - e as correlatas necessidades de saúde - se conectam com o cuidado ampliado que é esperado e preconizado pelos princípios e diretrizes do SUS. Desse modo, há uma relação entre o sistema de saúde e a dinâmica social que constitui os valores sociais sobre a proteção à saúde, a qual se amplia de acordo com o entendimento social sobre os modos de enfrentamento do processo de adoecimento. ${ }^{21}$

Com base nessa lógica é possível compreender que, para a consolidação e a legitimação desse sistema, é necessária uma conjuntura política-legal que estabeleça a necessidade da execução de políticas públicas que garantam os direitos fundamentais sociais a qualquer cidadão e sirva, inclusive, como amparo aos excluídos sociais. Essa é uma categoria entendida pelo processo de afastamento e enfraquecimento da participação de tais pessoas nas relações sociais, dadas as dificuldades para o exercício efetivo da cidadania, em seus contextos, sob o aspecto dos direitos, deveres e participação nas decisões político-sociais.

Todavia, a atenção do poder público voltada às PSR ainda é muito recente e consequência de várias lutas sociais e de direitos que aconteceram. O desinteresse ainda presente no Estado por essas populações demonstra a contradição tanto das ações como da opinião pública diante do tema, em colocações que alternam piedade, preocupação e assistencialismo com repressão, preconceito e indiferença. ${ }^{22}$ São essas nuances que revelam esse descaso e a falta de ações de proteção social do Estado que comportem, satisfatoriamente, o atendimento às PSR submetidas a diferentes vulnerabilidades e riscos.

A Política Nacional para a População em Situação de Rua (PNPSR) foi instituída pelo Decreto Presidencial n 7.053 , de 23 de dezembro de 2009, e implementada de forma descentralizada como uma ação de legitimação da existência e garantia de direitos das PSR. Essa política assegura os cuidados com a saúde das PSR, incluindo os serviços assistenciais e de albergamento presentes no território. ${ }^{23}$ Houve, também, o avanço trazido pelo Comitê Intersetorial de Acompanhamento e Monitoramento, com o mesmo decreto, além das conquistas advindas da publicação do Plano Operativo de Saúde para a População em Situação de Rua e a implantação do Programa CnaR, que prevê no Eixo 4 (norteador para os objetivos do presente estudo), o estabelecimento de estratégias para o fortalecimento da participação e do controle social como indispensável para a defesa dos direitos das PSR. ${ }^{24}$

Diante dessa realidade, a implementação da Lei Orgânica da Assistência Social (Lei n 8.742, de 7 de setembro de 1993) ratifica a tarefa do poder público, perante o reconhecimento de que a assistência social é direito do cidadão e dever do Estado. Com efeito, devem ser mantidos serviços e programas de atenção às PSR, provendo os mínimos sociais por meio de ações da iniciativa pública e da sociedade. ${ }^{25}$ 
Assim, projetos sociais e demais iniciativas voltam-se para a atenção à crescente demanda dessa população.

É essencial levar em consideração que a Política Nacional de Promoção da Saúde (PNPS) instituída pela Portaria MS/GM n 687 , de 30 de março de 2006, representa: ${ }^{26}$

"[...] uma estratégia de articulação transversal na qual se confere visibilidade aos fatores que colocam a saúde da população em risco e às diferenças entre necessidades, territórios e culturas presentes no nosso País, visando à criação de mecanismos que reduzam as situações de vulnerabilidade, defendam radicalmente a equidade e incorporem a participação e o controle sociais na gestão das políticas públicas". ${ }^{26}$

Além do aparato legal - e somados a ele - os movimentos sociais têm significativa importância na discussão de direitos humanos e de outros aspectos vinculados à cidadania das PSR. O protagonismo dessa discussão ganha novos contornos com o advento do Movimento dos Trabalhadores Sem Teto (MTST), o qual inaugura um movimento social com conquistas políticas concretas em termos das moradias populares, por meio da ocupação dos espaços públicos e da luta pela regulamentação. ${ }^{27}$ Nos 1990 , os moradores de rua foram recrutados pelo Movimento dos Trabalhadores Rurais Sem Terra (MST) para participar de seus acampamentos e ocupações rurais e obtiveram o apoio de entidades da sociedade civil. ${ }^{28}$ Posteriormente, segundo a cartilha de formação do Movimento Nacional da População de Rua (MNPR), o protagonismo nessa luta por direitos volta-se ao surgimento desse movimento primeiramente nas cidades de São Paulo e Belo Horizonte, com posterior repercussão nas demais regiões brasileiras. Em 2008, encontrou representatividade no Conselho Nacional de Assistência Social e tem como orientadores de sua organização e prática políticas os seguintes princípios: democracia, valorização do coletivo, solidariedade, ética e trabalho de base, e suas bandeiras de luta são: resgate da cidadania por meio de trabalho digno, salários suficientes para o sustento, moradia digna e atendimento à saúde.

Apesar dessas experiências, ainda há um caráter restrito de movimentos sociais aglutinadores que foram capazes de dar a devida visibilidade aos direitos humanos das PSR. ${ }^{22}$ Isso pode ser inferido das experiências de alguns movimentos, que persistem na luta por meio da mobilização social, na incessante busca de garantias de direito e cidadania dessas pessoas, firmando esse espaço social de diálogo e articulação. Entretanto, é notável que, no atual momento de crise do país, os atores que estão abertos a construir essas trocas e negociações compõem um campo ainda insólito de discussão, fator que revela a invisibilidade ainda atrelada não só às PSR, mas também aqueles que lutam por - e com - essas pessoas.

No âmago desse contexto social e político, é necessário atentar-se à forma como os serviços desenvolvem seu papel nos cuidados à saúde, tendo em vista os progressos advindos da legitimidade dos direitos e da cidadania conquistados historicamente. E, como perpetuam, solidificam ou dissipam as formas de encontro com as necessidades de saúde das distintas populações, suas reais demandas e concepções de saúde-doença, bem como a consonância ou dissonância da atuação em rede sobre o imbricamento de todas essas questões de interesse para a análise dessas atribuições.

Com efeito, pode-se analisar a complexidade do campo da saúde fazendo uso da colocação de Caponi: ${ }^{29}$

"[...] evidenciar que o âmbito dos enunciados, o âmbito dos discursos, está em permanente cruzamento com o âmbito do não-discursivo, do institucional. É por isso que a aceitação de 
determinado conceito implica muito mais que um enunciado, implica o direcionamento de certas intervenções efetivas sobre o corpo e a vida dos sujeitos, implica a redefinição desse espaço de onde se exerce o controle administrativo da saúde dos indivíduos". ${ }^{29}$

Cabe, portanto, a ponderação sobre o papel dos serviços e a atuação dos profissionais — na tarefa de ir além da lógica biomédica, protocolar e segmentada - ao se colocarem disponíveis ao cuidado dos usuários. $\mathrm{E}$, em vez disso - ou somado a isso - , fortalecer uma concepção de atenção que comporte a ordem do que está instaurado no discurso e nos corpos dos sujeitos, em suas concepções de saúdedoença, em suas histórias de vida, bem como naquilo que consideram como necessidades e demandas reais de saúde.

Diante do que preconiza a expressão dos cuidados em saúde - manifestadas por políticas, programas e serviços de saúde - e a consonância com os princípios e diretrizes do SUS, há uma estreita relação com a atenção à saúde enquanto estratégia do sistema e das práticas de cuidado. ${ }^{30}$ É previsto que todo sistema de serviços de saúde possua como metas principais: otimizar a saúde da população, apontar as causas das enfermidades e o manejo das doenças e minimizar as disparidades entre subgrupos populacionais (nos quais as PSR se inserem), para que não haja desvantagem sistemática em relação ao acesso a esses serviços e ao seu alcance. Essa premissa resume a responsabilidade deles para com seus usuários no que tange à prioridade de acesso, independentemente das díspares condições que apresentem.

Nesse sentido, colocar os serviços de saúde em análise é uma ideia que foi tensionada por AlmeidaFilho, o qual salienta que "é preciso questionar o sentido e o lugar das práticas pessoais, profissionais, institucionais e sociais que, de modo articulado, conformam os espaços em que a saúde se constitui". 6 Tais práticas são influenciáveis e influenciadas pela dinâmica das pessoas que necessitam de atenção - e por toda a complexidade inerente a elas - em prol do acesso e da disponibilidade de serviços, considerados da perspectiva e da concepção dos próprios usuários.

A utilização desses pressupostos permite a escuta atenta às pessoas que buscam cuidados em saúde, levando em conta suas necessidades como centro das intervenções e práticas. Isso por meio da apropriação indispensável dos discursos livremente apresentados pelos usuários, os quais são marcados por concepções próprias, que necessariamente não se limitam à lógica do atendimento pontual e meramente técnico, o qual pode se tornar meramente direcionado a uma reclamação/demanda isolada. Essas considerações afirmam a importância da subjetividade enquanto premissa inalienável dos usuários e dos trabalhadores da saúde, sendo possível a ampliação das ações de cunho restrito e técnico para um trabalho de interação social profundamente compassivo. ${ }^{31}$ Propõe-se a oferta de um atendimento implicado e permeado pela história de vida do usuário, valorizando sua autoria e autonomia em seu processo de cuidado e sua vinculação ao serviço, tendo em vista "a decisão, a liberdade e participação, que são os pontos fundamentais para o desempenho do autocuidado" ${ }^{32}$

A importância da caracterização desses atendimentos esbarra em algumas limitações na recepção e no acompanhamento da totalidade das demandas de saúde da população atendida nos serviços. Ao se pensar na integralidade da rede enquanto facilitadora para a qualidade e a equidade da atenção, ressalta-se a relevância da APS, cuja função estratégica é importante no elo que se constitui entre o sistema de saúde e as pessoas; isso explica a necessidade de se implantar uma articulada política intersetorial. ${ }^{33}$ De fato, a intersetorialidade, nesse sentido, representa uma genuína possibilidade de evitar o engessamento dos atendimentos, permitindo um fluxo dessas demandas. . $33,34^{3}$ 


\section{O papel da atenção primária à saúde}

AAPS refere-se ao "[...] conjunto de ações de saúde individuais, familiares e coletivas que envolvem promoção, prevenção, proteção, diagnóstico, tratamento, reabilitação, redução de danos, cuidados paliativos e vigilância em saúde, desenvolvida por meio de práticas de cuidado integrado e gestão qualificada, realizada com equipe multiprofissional e dirigida à população em território definido, sobre as quais as equipes assumem responsabilidade sanitária". ${ }^{35}$ Esse nível de atenção representa, via de regra, o primeiro contato dos indivíduos, da família e da comunidade com o sistema nacional de saúde, pelo qual os cuidados são levados aos lugares onde as pessoas vivem e trabalham, sendo um elemento de continuado processo de cuidado à saúde. ${ }^{22}$ Trata-se, pois, da principal porta de entrada e de comunicação com toda a Rede de Atenção à Saúde (RAS), sendo a Estratégia Saúde da Família (ESF) o principal recurso de configuração da APS e, também, o principal ordenador da atenção. ${ }^{30,36}$ Além da ESF, a atual Política Nacional de Atenção Básica (PNAB) — regulamentada pela Portaria $n^{\circ}$ 2.436, de 21 de setembro de 2017 - ratifica a inclusão da atenção para a população de rua com o protagonismo dos CnaR, a ampliação do número de municípios com Núcleos de Apoio à Saúde da Família (NASF) e a criação de unidades básicas de saúde (UBS) fluviais e ESF para as populações ribeirinhas.

A articulação que se faz necessária entre as equipes de APS/ESF, para cumprir com a sua proposta de resolutividade, está diretamente ligada à concepção de integralidade. Esta dá-se pela adequação das equipes, que passam a se basear nas demandas e nas necessidades de saúde da população, procurando abranger suas ações, contando com a ampliação oferecida por equipes de apoio e com articulações relativas a outros pontos de atenção da rede para a continuidade do cuidado. ${ }^{37}$

Nessa lógica, um importante atributo da APS a ser destacado para a discussão deste estudo é o referido "primeiro contato", o qual diz respeito ao acesso e à utilização do serviço de saúde para cada novo evento de saúde ou novo episódio de um mesmo evento, considerando-se como porta de entrada o serviço identificado pela população e a equipe como o primeiro recurso de saúde a ser buscado, quando há uma necessidade/problema de saúde. ${ }^{34,35}$ Ou seja, é nos serviços da APS que se espera que as pessoas — sejam elas quem forem e independentemente de suas demandas - sejam acolhidas em um serviço voltado para essa "livre iniciativa". A APS utiliza tecnologias de cuidado variadas para auxiliar no manejo das demandas e das necessidades de saúde do território, atentando-se para critérios de risco, vulnerabilidade, resiliência e para a premissa de acolher — com incondicional hospitalidade ${ }^{1}$ — qualquer demanda, necessidade de saúde ou sofrimento. ${ }^{35}$ Sendo assim, a organização dos processos de trabalho na APS opera por meio das diretrizes do acolhimento e do vínculo, de acordo com os quais a equipe multiprofissional se responsabiliza pelo cuidado. ${ }^{38}$

Com essa composição, atributos e objetivos, a utilização da APS no sistema de saúde brasileiro melhorou consideravelmente desde a criação da ESF, tanto pela ampliação do acesso das populações aos serviços como pela disponibilização de maiores ações de promoção, prevenção, diagnóstico, tratamento e reabilitação. ${ }^{39}$ Todavia, existem muitos desafios para o alcance da equidade e dos melhores resultados da saúde, como a valorização da APS na RAS, o aumento de sua resolutividade e o cuidado de enfocar as necessidades da população. Complementarmente a essas pontuações, estão os desafios apontados por Motta e Siqueira-Batista: ${ }^{39}$ "o desafio de compreender e praticar a integralidade na APS; o desafio da valorização e adequação do perfil dos profissionais/trabalhadores da ESF; a formação, a inserção e a práxis do agente comunitário de saúde; a dificuldade de trabalho em equipe nas unidades da ESF". ${ }^{39}$

Mesmo com esses obstáculos, são indiscutíveis os impactos da APS na saúde da população atendida. Nota-se o destaque desse nível de atenção como elemento norteador de análises capazes de identificar os 
fluxos presentes na RAS como um todo; ademais, são muitas as evidências de sua resolutividade, apesar das limitações. Trata-se, pois, de um local privilegiado para o exercício do cuidado e da regulação do acesso — com destaque para a microrregulação — , referente às decisões profissionais e à priorização de casos mediante suas análises. Sendo assim, a resolutividade está atrelada ao vínculo construído, ao suporte e à articulação da rede. ${ }^{37}$ Esses são argumentos que estão relacionados às respostas sobre a problematização da efetividade e do alcance da rede primária de cuidados à saúde por meio das estratégias, dispositivos, serviços e normas que a compõem, na medida em que "nos serviços de saúde há uma multiplicidade de redes operando em conexões entre si, em diversas direções e sentidos, construindo linhas de produção do cuidado" ${ }^{40}$

As linhas de produção de cuidado são de extrema importância para se pensar a organização das equipes e do trabalho realizado, pelos profissionais, para a efetividade do que se pretende alcançar com a organização da APS. Isso se deve, como citado, principalmente à forma com que se dão os encontros entre as equipes e os usuários, e é com base neles que se torna possível avaliar esse critério de resolutividade e de abrangência das ações.

\section{Consultório na Rua}

A atenção à saúde deve ser ofertada a todos de modo equitativo, portanto a responsabilidade sobre as PSR deve ser de qualquer profissional e serviço do SUS, especialmente da APS, tendo em vista o objetivo de ampliar esse alcance à rede de atenção. Com efeito, essa rede é evidentemente uma referência para cuidados das PSR, na medida em que considera a dinâmica territorial e relacional dos usuários para a articulação de estratégias de cuidado, consubstanciado em termos dos CnaR. ${ }^{35}$

O CnaR é um serviço importante na direção desse cuidado. Foi instituído pela PNAB, a qual estabeleceu as diretrizes de organização das equipes do CnaR. Destaca-se a necessidade de integração intersetorial entre as políticas de saúde e as demais políticas públicas, com o intuito de melhorar a capacidade de resposta às demandas e necessidades de saúde das PSR. ${ }^{41}$

A equipe do CnaR tem "composição variável, responsável por articular e prestar atenção integral à saúde de pessoas em situação de rua ou com características análogas em determinado território, em unidade fixa ou móvel, podendo ter as modalidades e respectivos regramentos descritos em portaria específica". ${ }^{35}$ As ações são desenvolvidas na rua, em instalações específicas, e também articuladas às demais equipes de APS do território, ao NASF, aos Centros de Atenção Psicossocial (CAPS), à Rede de Urgência e aos serviços e instituições do Sistema Único de Assistência Social (SUAS), entre outras instituições públicas e da sociedade civil. Ademais, o CnaR é uma equipe volante vinculada a pelo menos uma UBS e que preconiza a construção de vínculos e a ampliação do acesso das PSR aos serviços de saúde, utilizando uma abordagem proativa dialogada com os movimentos e os territórios dos usuários. ${ }^{37}$ As lógicas de cuidado às quais esses instrumentos se propõem têm um sentido ampliado, na medida em que já ocorre o encontro no território com a população, o qual permite a construção de vínculos que vão além do simples atendimento, em prol da produção de ações que potencializem a saúde. ${ }^{42}$

O CnaR é, então, um serviço que atualmente está interligado à APS, implementado em seus atributos de primeiro contato, vínculo longitudinal, integralidade e coordenação da atenção e, por isso, pressupõe em sua formulação a aptidão à prestação do cuidado integral necessário às populações vulneráveis, como as PSR. ${ }^{43}$

Diante das especificidades desses usuários, as equipes de CnaR compõem umas das estratégias que propicia tal cuidado, a redução de danos (RD). Esta é considerada uma importante diretriz do cuidado 
e uma estratégia que permite o contato e a aproximação com essas pessoas, para escutar suas vozes, seus silêncios que traduzem preconceito, estigma, sofrimento e exclusão social. ${ }^{44}$ De acordo com a política e a estratégia de RD, procura-se construir formas de manejo do cuidado considerando a singularidade de cada um dos usuários. ${ }^{45} \mathrm{O}$ CnaR constitui-se, pois, em um serviço que se presta a ir até o lugar onde o usuário circula, em seu território geográfico, existencial e relacional; isto posto, torna-se essencial a intersetorialidade para que seu trabalho se faça possível na rede. Essa visão de território acompanha a consolidação de espaços que realizam essas e outras práticas de cuidado e ações de saúde por meio da priorização de aspectos singulares que preservam suas especificidades. ${ }^{46,47}$

O desafio está em superar as práticas que privilegiam a manifestação individual das alterações da saúde sem considerá-las à luz da saúde coletiva, o que significa problematizar o cuidado pela criação de dispositivos atravessados por múltiplos saberes e práticas, mais resolutivos para lidar com demandas que vão dos sujeitos à cidadania, dos indivíduos aos coletivos. Além disso, conta-se com o princípio da universalidade de acesso à saúde como um dos eixos éticos que direcionam as práticas de cuidado às PSR, as quais estão submetidas a um viés de exclusão social. ${ }^{43} \mathrm{~A}$ promoção da saúde articula-se por meio da singularidade de cada sujeito em seu território e em atenção à construção de estratégias que facilitem a ampliação do grau de saúde e de qualidade de vida, tendo em vista a singularidade do sujeito. ${ }^{42}$

Diante da breve contextualização desse dispositivo ${ }^{36,42}$ - e para além do que está baseado e instaurado em portarias e leis - , existe o reconhecimento das realidades e das experiências vivenciadas pelos profissionais, usuários e familiares que estão envolvidos na lógica de cuidado proposta pelo CnaR. ${ }^{48-50}$

\section{CONSIDERAÇÕES FINAIS}

O par saúde-doença representa um binômio de explícita complexidade, cujas significações, em termos das demandas e das necessidades de saúde, têm implicação direta na atenção à saúde das PSR. Cabe a reflexão, de fato, sobre a realidade social impressa nos corpos e nos discursos desses usuários do SUS, em termos da promoção da saúde e dos distintos determinantes do adoecimento, o que permite um melhor planejamento das ações de cuidado, vinculadas aos indivíduos, seus territórios e seus contextos.

Com efeito, devem-se considerar os profissionais e os usuários como partícipes do processo de gestão compartilhada da atenção à saúde. A consubstanciação desse processo ocorre, em grande medida, mediante a articulação de redes e de serviços integrados, com destaque para os CnaR, como se procurou mostrar no presente ensaio. Considerando-se o alcance dos princípios e das diretrizes do SUS, torna-se necessário aprimorar os processos reflexivos dirigidos à práxis do cuidado das PSR, construída diuturnamente na composição entre: 1. o essencial respeito à autodeterminação do outro; e 2. a incondicional hospitalidade daquele que se dispõe ao amparo.

\section{CONFLITOS DE INTERESSE}

Nada a declarar.

\section{CONTRIBUIÇÃO DOS AUTORES}

FGF: Administração do projeto, Conceituação, Escrita - primeira redação, Escrita - revisão e edição, Investigação. RSB: Conceituação, Escrita - primeira redação, Escrita - revisão e edição, Investigação. 


\section{REFERÊNCIAS}

1. Faria FG, Siqueira-Batista, R. (Bio)ética e população em situação de rua: entre Agamben e Derrida. Rev Bioét 2020;28(4):62836. http://doi.org/10.1590/1983-80422020284426

2. Boff L. Saber cuidar. Ética do humano - compaixão pela terra. 20ª ed. Petrópolis: Editora Vozes; 2014.

3. Assumpção ELA. A vida em cenas de uso de crack: ensaio de análise institucional e bioética [tese de doutorado]. Niterói: Universidade Federal Fluminense; 2016.

4. Santos ACB, Silva AF, Sampaio DL, Sena LX, Gomes VR, Lima VLA. Antropologia da saúde e da doença: contribuições para a construção de novas práticas em saúde. Revista do NUFEN 2012;4(2):11-21.

5. Scliar M. História do conceito de saúde. Physis Rev Saúde Coletiva 2007;17(1):29-41. https://doi.org/10.1590/S010373312007000100003

6. Almeida Filho N. O que é saúde? Rio de Janeiro: Editora Fiocruz; 2011.

7. Santos BS. Um discurso sobre as ciências. Porto: Afrontamento; 1987.

8. Minayo MCS. Saúde: concepções e políticas públicas. In: Amâncio Filho A, Moreira MCGB. Saúde, trabalho e formação profissional. Rio de Janeiro: Fiocruz; 1997. p. 31-9 [acessado em 20 out. 2021]. Disponível em: http://books.scielo.org/ id/9tc7r/pdf/amancio-9788575412787-04.pdf

9. Alves PC, Rabelo MC. Repensando os estudos sobre representações e práticas em saúde/doença. In: Alves PC, Rabelo MC. Antropologia da saúde: traçando identidade e explorando fronteiras. Rio de Janeiro: Editora Fiocruz; 1998. p. 107-21 [acessado em 20 out. 2021]. Disponível em: http://books.scielo.org/id/by55h/pdf/alves-9788575414040-07.pdf

10. Monken M, Barcellos C. Vigilância em saúde e território utilizado: possibilidades teóricas e metodológicas. Cad Saúde Pública 2005;21(3):898-906. https://doi.org/10.1590/S0102-311X2005000300024

11. Canesqui AM. Notas sobre a produção acadêmica de antropologia e saúde na década de 80. In: Alves PC, Minayo MCS. Saúde e doença: um olhar antropológico. Rio de Janeiro: Editora Fiocruz; 1994. p. 13-32 [acessado em 20 out. 2021]. Disponível em: http://books.scielo.org/id/tdj4g/pdf/alves-9788575412763-02.pdf

12. Sarti C. Corpo e doença no trânsito dos saberes. Rev Bras Ciên Soc 2010;25(74):77-90. https://doi.org/10.1590/S010269092010000300005

13. Guimarães CF, Meneghel SN. Subjetividade e saúde coletiva: produção de discursos na re-significação do processo saúdedoença no pós-moderno. Revista Mal-Estar e Subjetividade 2003;3(2):353-71.

14. Batistella CEC. Análise da situação de saúde: principais problemas de saúde da população brasileira. In: Fonseca AF, Corbo AMDA. O território e o processo saúde-doença. Rio de Janeiro: EPSJV/Fiocruz; 2007. p. 121-58.

15. Silva JPV, Batistella C, Gomes ML. Problemas, necessidades e situação de saúde: uma revisão de abordagens para a reflexão e ação da equipe de saúde da família. In: Fonseca AF. O território e o processo saúde-doença. Rio de Janeiro: EPSJV/Fiocruz; 2007. p. 159-176.

16. Teixeira CF. Modelos de Atenção voltados para a qualidade, efetividade, equidade e necessidades prioritárias de saúde. In: Teixeira CF, Paim JS, Villasbôas AL. Promoção e Vigilância da Saúde. Salvador: ISC; 2002. p. 81-2.

17. Luz MT. Especificidade da contribuição dos saberes e práticas das Ciências Sociais e Humanas para a saúde. Saúde Soc 2011;20(1):22-31. https://doi.org/10.1590/S0104-12902011000100004

18. Moraes DE, Canôas SS. O conceito de "território" e seu significado no campo da Atenção Primária à Saúde. Rev Des Social 2013;1(9):49-57.

19. Campos CMS, Bataiero MO. Necessidades de saúde: uma análise da produção científica brasileira de 1990 a 2004. Interface - Comunic Saúde Educ 2007;11(23):605-18. https://doi.org/10.1590/S1414-32832007000300014

20. Minayo MCS. Saúde-doença: uma concepção popular da etiologia. Cad Saúde Pública 1988;4(4):363-81. https://doi. org/10.1590/S0102-311X1988000400003

21. Lobato LVC, Giovanella L. Sistemas de saúde: origens, componentes e dinâmica. In: Giovanella L, Escorel S, Lobato LVC, Noronha JC, Carvalho A. Políticas e Sistema de Saúde no Brasil. Rio de Janeiro: Editora Fiocruz; 2012. p. 89-120.

22. Costa APM. População em situação de rua: contextualização e caracterização. Textos \& Contextos 2005;4(1):1-15.

23. Brasil. Presidência da República. Casa Civil. Subchefia para Assuntos Jurídicos. Decreto $n^{\circ} 7.053$, de 23 de dezembro de 2009. Institui a Política Nacional para a População em Situação de Rua e seu Comitê Intersetorial de Acompanhamento e Monitoramento, e dá outras providências. Diário Oficial da União, de 24 de dezembro de 2009. Seção 1. p. 16. [acessado em 15 fev. 2018] Disponível em: http://www.planalto.gov.br/ccivil_03/_ato2007-2010/2009/decreto/d7053.htm.

24. Brasil. Ministério da Saúde. Secretaria de Gestão Estratégica e Participativa, Departamento de Apoio à Gestão Participativa. Saúde da população em situação de rua: um direito humano. Brasília: Ministério da Saúde; 2014. [acessado em 20 out. 2021]. Disponível em: https://bvsms.saude.gov.br/bvs/publicacoes/saude_populacao_situacao_rua.pdf

25. Brasil. Presidência da República. Casa Civil. Subchefia para Assuntos Jurídicos. Lei $n^{\circ} 8.742$, de 07 de dezembro de 1993. Dispõe sobre a organização da Assistência Social e dá outras providências. Diário Oficial da União, Seção 1 , de 8 de dezembro de 1993, p. 18769. [acessado em 15 fev. 2018]. Disponível em: http://www.planalto.gov.br/ccivil_03/Leis/ L8742compilado.htm.

26. Brasil. Ministério da Saúde. Secretaria de Vigilância em Saúde. Secretaria de Atenção à Saúde. Política Nacional de Promoção da Saúde: PNPS: revisão da Portaria MS/GM n 687, de 30 de março de 2006. Brasília: Ministério da Saúde; 2015. [acessado em 20 out. 2021]. Disponível em: https://bvsms.saude.gov.br/bvs/publicacoes/pnps_revisao_portaria_687. pdf 
27. Varanda W, Adorno RCF. Descartáveis urbanos: discutindo a complexidade da população de rua e o desafio para políticas de saúde. Saúde e Sociedade 2004;13(1):56-69.

28. Gohn MG. Movimentos sociais e redes de mobilização civis no Brasil contemporâneo. Petrópolis: Vozes, 2013.

29. Caponi S. Georges Canguilhem y el estatuto epistemológico del concepto de salud. História, Ciências, Saúde 1997;IV(2):287307. https://doi.org/10.1590/S0104-59701997000200006

30. Matta GC, Morosini MGV. Atenção primária à saúde. In: Pereira IB. Dicionário da educação profissional em saúde. Rio de Janeiro: EPSJV; 2008. p. 44-9. [acessado em 20 out. 2021]. Disponível em: https://www.epsjv.fiocruz.br/sites/default/files/ 143.pdf

31. Coelho MO, Jorge MSB. Tecnologia das relações como dispositivo do atendimento humanizado na atenção básica à saúde na perspectiva do acesso, do acolhimento e do vínculo. Ciên Saúde Coletiva 2009;14(Supl 1):1523-31. https://doi. org/10.1590/S1413-81232009000800026

32. Noronha R. Experiência participativa mobilizadora de enfermagem: condições prévias para o autocuidado. Rev Bras Enf 1986;39(1):34-43. https://doi.org/10.1590/S0034-71671986000100005

33. Hallais JAS, Barrros NF. Consultório na Rua: visibilidades, invisibilidades e hipervisibilidade. Cad Saúde Pública 2015;31(7):1497-504. https://doi.org/10.1590/0102-311X00143114

34. Declaração de Alma-Ata sobre cuidados primários. Conferência Internacional sobre Cuidados Primários em Saúde; 1978. [acessado em 20 out. 2021]. Disponível em: https://bvsms.saude.gov.br/bvs/publicacoes/declaracao_alma_ata.pdf

35. Brasil. Ministério da Saúde. Gabinete do Ministro. Portaria $n^{\circ} 2.436$, de 21 de setembro de 2017. Aprova a Política Nacional de Atenção Básica, estabelecendo a revisão de diretrizes para a organização da Atenção Básica, no âmbito do Sistema Único de Saúde (SUS). Brasília: Ministério da Saúde; 2017. [acessado em 20 out. 2021]. Disponível em: https://bvsms. saude.gov.br/bvs/saudelegis/gm/2017/prt2436_22_09_2017.html

36. Bermudez KM, Siqueira-Batista R. "Many holes tied together with ropes": the concept of network for mental health professionals. Saude Soc 2017;26(4):904-19. https://doi.org/10.1590/S0104-12902017170298

37. Brasil. Ministério da Saúde. Secretaria de Atenção à Saúde. Departamento de Atenção Básica. Núcleo de Apoio à Saúde da Família. Brasília: Ministério da Saúde; 2014. [acessado em 20 out. 2021]. Disponível em: https://bvsms.saude.gov.br/bvs/ publicacoes/nucleo apoio saude familia cab39.pdf

38. Silva LAN, Harayama RM, Fernandes FP, Lima JG. Acesso e acolhimento na Atenção Básica da região Oeste do Pará. Saúde Debate 2019;43(122):742-54. https://doi.org/10.1590/0103-1104201912207

39. Motta LCS, Siqueira-Batista R. Estratégia Saúde da Família: clínica e crítica. Rev Bras Educ Med 2015;39(2):196-207. https://doi.org/10.1590/1981-52712015v39n2e00912014

40. Franco TB. As redes na micropolítica do processo de trabalho em saúde. In: Pinheiro R, Matos RA. Gestão em redes. Rio de Janeiro: LAPPIS-IMS/UERJ-ABRASCO; 2006. [acessado em 20 out. 2021]. Disponível em: http://www.uesc.br/ atencaoasaude/publicacoes/redes_na_micropolitica_do_processo_trabalho_-_tulio_franco.pdf

41. Brasil. Ministério da Saúde. Gabinete do Ministro. Portaria n ${ }^{\circ} 122$, de 25 de janeiro de 2011 . Define as diretrizes de organização e funcionamento das Equipes de Consultório na Rua. Diário Oficial da União n 19, Seção 1, p. 46, de 26 de janeiro de 2012. [acessado em 22 jan. 2018]. Disponível em: http://bvsms.saude.gov.br/bvs/saudelegis/gm/2012/prt0122_25_01_2012.html

42. Macerata IM. Experiência POP RUA: implementação do "Saúde em Movimento nas Ruas" no Rio de Janeiro, um Dispositivo Clínico/Político na Rede de Saúde do Rio de Janeiro. Rev Polis e Psique 2013;3(2):207-19. https://doi.org/10.22456/2238152X.46178

43. Engstrom EM, Teixeira MB. Equipe "Consultório na Rua" de Manguinhos, Rio de Janeiro, Brasil: práticas de cuidado e promoção da saúde em um território vulnerável. Ciên Saúde Coletiva 2016;21(6):1839-48. https://doi.org/10.1590/141381232015216.0782016

44. Jorge JS, Corradi-Webster CM. Consultório de Rua: contribuições e desafios de uma prática em construção. Saúde Transform Soc 2012;3(1):39-48.

45. Santos VE, Soares CB, Campos CMS. Redução de danos: análise das concepções que orientam as práticas no Brasil. Physis Revista da Saúde Coletiva 2010;20(3):995-1015. https://doi.org/10.1590/S0103-73312010000300016

46. Santos EC, Azevedo FGS. As práticas itinerantes de cuidado no contexto da saúde mental no Brasil. Rev Psi Divers Saúde 2016;5(1):95-105. https://doi.org/10.17267/2317-3394rpds.v5i1.851

47. Araujo E, Schramm FR. Princípios da clínica na rua e os funcionamentos do crack. Rev Bioét 2017;25(3):473-81. http://doi. org/10.1590/1983-80422017253204

48. Teixeira MB, Belmonte P, Engstron EM, Lacerda A. Os invisibilizados da cidade: o estigma da população em situação de rua no Rio de Janeiro. Saúde Debate 2019;43(7):92-101. https://doi.org/10.1590/0103-11042019S707

49. Viegas SMF, Nitschke RG, Bernardo LA, Tholl AD, Borrego MAR, Soto PJL, et al. Quotidiano de equipes de consultório na rua: tecendo redes para a promoção da saúde. Esc Anna Nery 2021;25(3):e20200222. https://doi.org/10.1590/2177-9465EAN-2020-0222

50. Campos A. População de rua: um olhar da educação interprofissional para os não visíveis. Saúde Soc 2018;27(4):997-1003. https://doi.org/10.1590/S0104-12902018180908 